DOI: $10.34031 / 2618-7183-2021-4-4-5-10$

\author{
Il ina T.N. *, Doctor of Engineering Sciences (Advanced Doctor), Professor, \\ Orlov P.A., Postgraduate, \\ Belgorod State Technological University named after V.G. Shukhov, Russia, \\ Chizhov A.V., Doctor of Science, \\ "Romet", LLC, Head of Laboratory, city of Penza, Russia \\ *Corresponding author E-mail: ilina50@rambler.ru
}

\title{
INFLUENCE OF MATERIAL STRUCTURE ON THE MAGNETOSTRICTIVE PROPERTIES OF A RADIATOR FOR DEFROSTING HEAT EXCHANGERS OF VENTILATION EQUIPMENT
}

\begin{abstract}
: the article deals with the properties of ferromagnetics and their behaviour in an external magnetic field. The conditions under which magnetism occurs in materials are shown and the choice of material for a magnetostrictive emitter is justified. The composition and properties of permendur as the most suitable material for the manufacture of magnetostrictive radiators are presented. It is shown that for the manufacture of the magnetostrictor it is feasible to use electro-erosion equipment for cutting packages from permendur compared to the costly and cumbersome method of stamping in a matrix of a particular shape. Tests were carried out on a duralumin heat exchanger with artificial frostbite. The evaporator was fed with refrigerant at $0.22 \mathrm{MPa}$, which corresponds to the boiling point of $\mathrm{R} 410 \mathrm{a}$ refrigerant at $35^{\circ} \mathrm{C}$, by means of a refrigerant line made of aluminium pipes. Frostbite was then produced by applying moist air using an ultrasonic steam generator. Frost on the evaporator surface is discharged by means of a magnetostrictor mounted on the heat exchanger. The proposed method allows for the most effective cleaning of the surfaces of heat exchangers of ventilation equipment from scale, fouling and other mechanical deposits by means of mechanical vibrations.
\end{abstract}

Keywords: ferromagnetics, permanganese, magnetostriction, heat pump, ice, evaporator, heat exchanger

\section{Introduction}

Ultrasound is used in various technological processes, medicine, energy, echolocation and defectoscopy. The ultrasonic vibrations are produced by generators, in which an obstacle is placed in the path of the gas or liquid flow and the passage through this obstacle creates mechanical vibrations. Electromechanical transducers are another way to generate ultrasonic vibrations. They convert electrical current vibrations into mechanical vibrations. As part of a building heating equipment project, the need arose to use ultrasonic vibrating systems to clean the surface of various heat exchangers of various impurities and ice. The oscillating circuit, which used piezoceramic mechanical oscillators, revealed a number of disadvantages, the main of which was the small amplitude of oscillation that a frequency radiator based on the piezoelectric effect is capable of producing. As a mechanical oscillator, it was decided to manufacture a radiator based on the magnetostriction effect, which is based on doment theory. Experiments have been carried out on the joint operation of an evaporator with an oscillating circuit at positive temperatures.

\section{Methods and Materials}

An electron moving in orbit forms a circular current which has the opposite direction to the electron's motion, the current strength has a value of I

$$
\mathbf{I}=\frac{e}{\mathrm{~T}}
$$

where $e$ is the charge of the electron, $\mathrm{T}$ is the orbital period of the electron.

The modulus of the orbital magnetic moment of the electron $\rho$, given its orbital area and linear velocity, is as follows:

$$
\rho=\frac{e c v}{2}
$$

where $\nu$ is the velocity of the electron, $\tau$ is the radius of the electron's orbit.

In addition to the orbital magnetic moment, the electron has a mechanical orbital moment $\ell$ : 


\section{$\ell=m v \tau$}

where $m$ is the mass of the electron.

The vector of the orbital mechanical momentum of the electron is opposite to the orbital magnetic momentum of the electron. If we make a relationship between the differently directed moments by combining the two formulas, we get:

$$
\rho=\frac{e}{2 m} \ell
$$

The ratio of the magnetic moment to the mechanical momentum of the electron is called the gyromagnetic ratio, or magnetomechanical ratio, and is denoted by $\gamma$ :

$$
\frac{\rho}{\ell}=\frac{e}{2 m}=\gamma
$$

The gyromagnetic ratio is characterised by the fact that different chemical elements have specific values, for ferromagnetic bodies the gyromagnetic ratio is equal $\frac{e}{m}$. This is because ferromagnetism is due to spin and not orbital magnetic moment. In elements such as Fe-iron, Co-cobalt, there are atoms in which the internal electron orbitals are under-constructed. According to Pauli theory, electrons in orbitals are arranged in pairs with opposite spins, electrons in unoccupied orbitals combine with other such electrons to form local regions-magnetic domains, which are up to several micrometres in size. The ability of a substance to acquire magnetic moment when exposed to a magnetic field has a quantitative characteristic and is proportional to the strength of the magnetic field and the magnetic susceptibility:

$$
j=\lambda \mathrm{H}_{3}
$$

where $\boldsymbol{j}$ - magnetisation, $\boldsymbol{\lambda}$ - magnetic susceptibility, $\mathrm{H}$ - external magnetic field strength.

Magnetisation $j$ is characterised by saturation energy and does not increase as the magnetic field strength increases further, reaching its maximum value. As magnetic field induction decreases, magnetisation decreases more slowly and will retain the residual magnetisation characteristic of the magnetically hard materials used to build permanent magnets. In magnetically soft materials the residual magnetisation requires less energy for remagnetisation (low coercive force) and the hysteresis loop is narrow [1]. The term magnetic hesteresis comes from the Greek

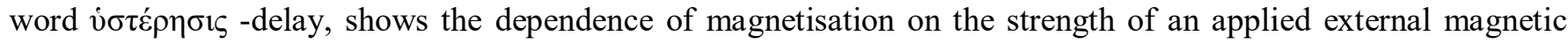
field, and also shows the lag of magnetisation from the magnetic field strength [2-5].

\section{Results and Discussions}

The most suitable material for manufacturing a magnetostrictor radiator is claim materials such as permendure, alfer, nickel. The 49K2F and 49K2FA have a high magnetic induction of technical saturation, but they are sensitive to mechanical influences due to displacement of the domain structures, which require restoration. The permendure provided was sent for chemical analysis by means of an optical emission spectrochemical analyser.

The analysis showed that the permendur alloy corresponds to grade $49 \mathrm{~K} 2 \mathrm{~F}$ and is suitable for manufacturing a core for a magnetostrictive radiator (Table 1). 


\begin{tabular}{|c|c|c|c|c|c|c|c|}
\hline \multicolumn{8}{|c|}{ Permendur alloy composition, $\%$} \\
\hline & $\mathrm{Fe}$ & $\mathrm{c}$ & $S i$ & $M n$ & $p$ & $\$$ & $\mathrm{Cr}$ \\
\hline i & 49,0 & 0,0077 & 0,154 & 0,156 & 0,0179 & 0,0032 & 0,0349 \\
\hline 2 & 48,7 & 0,0071 & 0,158 & 0,157 & 0,0190 & $c, 0093$ & 0,0274 \\
\hline Average & 49.8 & 0,0074 & & & $0: 0184$ & 0.0093 & 0,0311 \\
\hline & Mo & $\mathrm{Ni}$ & Al & $\mathrm{Co}$ & $\mathrm{Cu}$ & No & $T i$ \\
\hline 1 & 0.0213 & 0,0082 & 0.0901 & 48,1 & 0,0604 & $<0,0050$ & 0,0140 \\
\hline 2 & 0,0181 & $<0,0050$ & 0,0557 & 48,5 & 0,0840 & $<0,0050$ & 0,0133 \\
\hline Average & 0,0197 & $<0,0050$ & 0,0729 & 48,3 & 0,0722 & $<0,0050$ & 0,0136 \\
\hline & $v$ & h' & $\mathrm{Pb}$ & & & & \\
\hline 1 & 2,10 & 0,109 & 0,0112 & & & & \\
\hline 2 & $2: 12$ & 0,0231 & 0.0092 & & & & \\
\hline Average & & 0,0662 & 0,0102 & & & & \\
\hline
\end{tabular}

In the production of core elements for magnetostrictive radiators, the punching method from permendur sheets is used, but this method requires a special mould of a specific shape, deburring and assembly into packages. Changing the geometric dimensions of the core requires a different shaped die, the production cost and manufacturing time are only cost-effective on an industrial scale. It was decided to manufacture a prototype magnetostrictor using electroerosion equipment for cutting packages from 49K2F grade permendur [6].

Electrical discharge equipment uses a short-lived electric arc through an electrode as the basis of its operation when cutting metal. This arc pierces the metal, the arc lasts for a very short time and does not have time to deform the metal and maintains the integrity of the electrode. The flow of ionised plasma is about one millimetre thick, making the cut very precise and requiring no subsequent machining of the workpiece [7]. After fabrication of the magnetostrictive emitter package, a sample was taken to detect changes in the chemical composition on the surface. An electron microscope was used for this purpose [8].

On the slice of the sample, the area highlighted by the upper green circle marks the core material area. The earlier lack of copper admixture can be explained by the fact that the electrode through which the pulsed electric current is passed in the process of electrical discharge cutting contains elements which contain $\mathrm{Cu}$. The areas containing dendrites (the area highlighted by the yellow circle at the bottom) were further investigated $[8,10]$. The diagram shows the effect of electrical discharge cutting on the structure and composition of the workpiece (Fig. 1), where yellow indicates samples from the base metal area and the black curve indicates samples taken in the dendroid area. For ease of comparison, the chart data is tabulated (Table 2). The spectrogram is shown in Fig. 2.

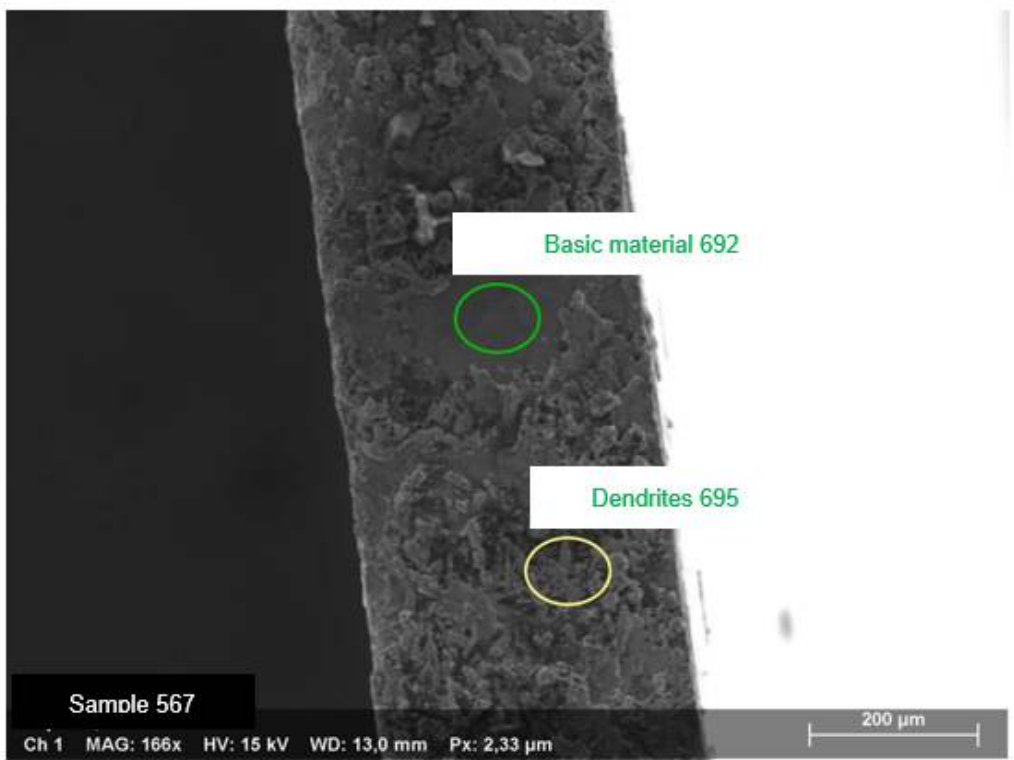

Fig. 1. Material structure 
Our research has shown the promise and relevance of using renewable energy sources in heat supply systems of engineering systems using heat pumps [11,12]. Compared to the capital and operating costs, air-source heat pumps are viable. However, in low temperatures in winter there is the problem of frost on the heat exchanger surface, which significantly reduces the conversion efficiency and requires defrosting costs. A promising method of deicing using mechanical vibrations has been proposed [13-15]. In order to be effective, it is necessary to develop a way of attaching the emitter to the surface of the heat exchanger and to select a material with high magnetostrictive properties.

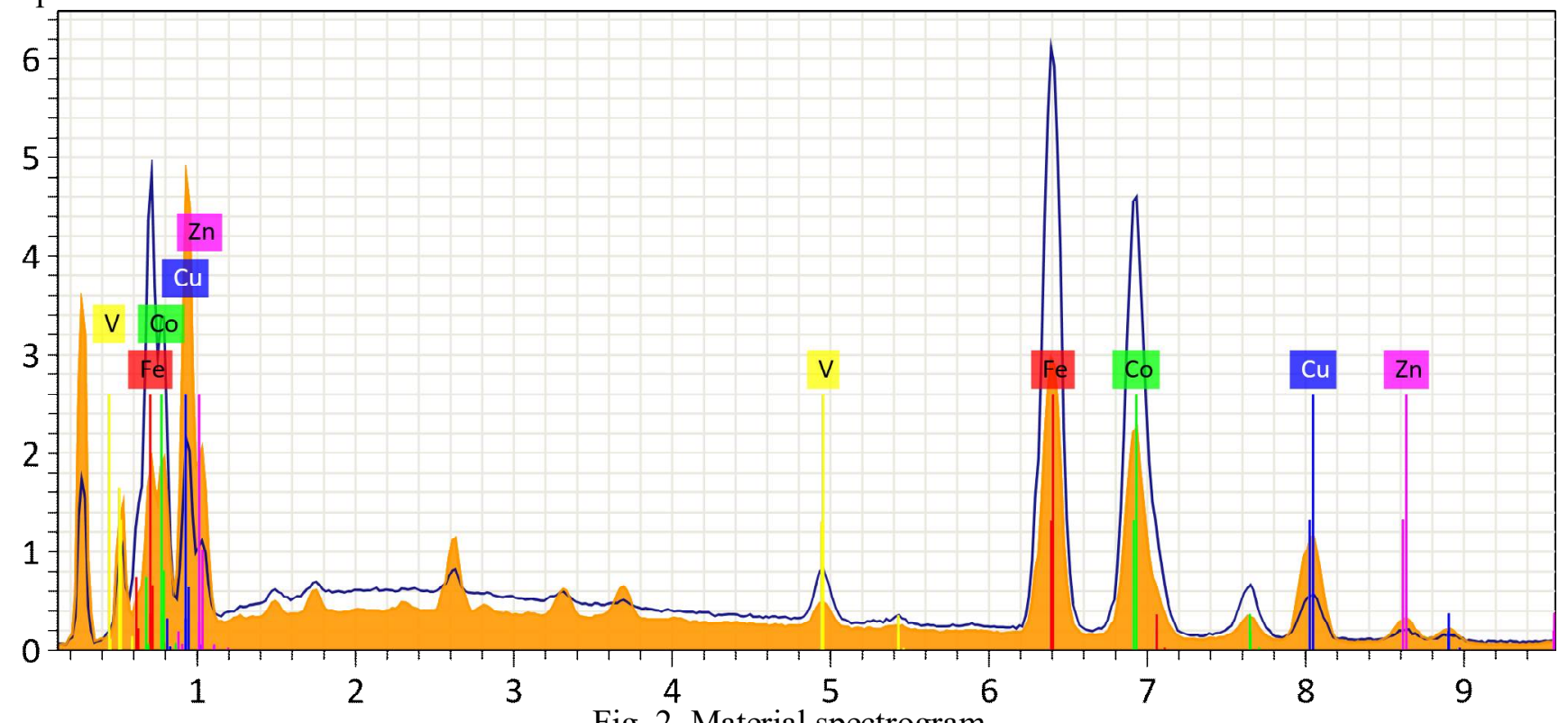

Fig. 2. Material spectrogram

Table 2

Chemical composition of the material components

\begin{tabular}{lccccc}
\multicolumn{1}{r}{ Spectrum } & V & Fe & Co & Cu & Zn \\
Basic material 692 & 1,75 & $\mathbf{4 3 , 4 9}$ & $\mathbf{4 4 , 0 7}$ & $\mathbf{8 , 2 1}$ & $\mathbf{2 , 4 8}$ \\
Dendrites 695 & 1,33 & $\mathbf{3 0 , 0 3}$ & $\mathbf{3 0 , 3 9}$ & $\mathbf{2 9 , 0 5}$ & $\mathbf{9 , 2 1}$ \\
Mean & $\mathbf{1 , 5 4}$ & $\mathbf{3 6 , 7 6}$ & $\mathbf{3 7 , 2 3}$ & $\mathbf{1 8 , 6 3}$ & $\mathbf{5 , 8 4}$ \\
Sigma & $\mathbf{0 , 2 9}$ & $\mathbf{9 , 5 2}$ & $\mathbf{9 , 6 8}$ & $\mathbf{1 4 , 7 4}$ & $\mathbf{4 , 7 5}$ \\
SigmaMean & $\mathbf{0 , 2 1}$ & $\mathbf{6 , 7 3}$ & $\mathbf{6 , 8 4}$ & $\mathbf{1 0 , 4 2}$ & $\mathbf{3 , 3 6}$
\end{tabular}

A heat exchanger made of D16 $\mathrm{t}$ alloy was designed and manufactured as an experimental prototype for the evaporator of the air-source heat pump outdoor unit, with properties most satisfactory for mechanical vibration passage, thermal conductivity, and chemically neutral to synthetic ROE oils and R 410a refrigerant (Fig. 3). The heat exchanger is manufactured in a monolithic version from $50 \mathrm{~mm}$ thick sheet metal, machined on a CNC milling machine. The total mass of the product was $12 \mathrm{~kg}$, which corresponds to a dissipated mass to excite an oscillating circuit with an energy requirement of $15 \mathrm{Wh}$. The permendulum core for vibration transmission to the evaporator is attached by means of a waveguide using an alloy obtained experimentally in the laboratory. The alloy is made up of different metals, with copper and silver with various metal impurities as a base. It may have variations in composition and methods of manufacture. The main prerequisite for efficient operation is that the radiator is securely fastened to the heat exchanger for the best possible transmission of vibrations when the core end is displaced. Under low-temperature operation and high-frequency vibration, fixing by means of bolted joints and epoxy compounds lost the ability to transmit a given frequency and force, which worsened the effect of entering the evaporator resonance over time of experimentation.

This problem was solved by pre-stressing the metal, where the elements proved to be mutually self-attractive to each other, forming a bond that minimised wave dispersion and reflection at the media boundary. Further, in our case it was required to abandon the use of a cooling shell with water circulation to cool the permendulum core, as the operating modes of the evaporator do not allow the use of water as a cooling liquid due to its freezing, the use 
of various non-freezing compositions also caused a number of restrictions on the oscillating circuit operation in the low-temperature mode. Solving the problem of core cooling resulted in a simplified design and reduced power consumption, which also improved the magnetostrictive properties of the radiators. The evaporator was fed with refrigerant at $0.22 \mathrm{MPa}$, which corresponds to the boiling point of $\mathrm{R} 410 \mathrm{a}$ refrigerant at $35^{\circ} \mathrm{C}$, by means of a refrigerant line made of aluminium pipes. Frostbite was then produced by applying moist air using an ultrasonic steam generator.

When the evaporator outlet temperature drops below the critical overheating point, a low pressure switch is normally triggered in heat pumps and the defrosting process of the outdoor unit evaporator is initiated by various methods, the most common being the use of hot gas and electricity. In our laboratory setup, the low-pressure switch operation has the function of indirectly monitoring the degree of frostbite on the evaporator heat transfer surfaces. The signal is fed to the controller which is responsible for the oscillating circuit operation. This operation of the deicing system does not require stopping the heat recovery process of the air removed from the building. The experiments showed the effectiveness of the de-icing method (Fig. 3).

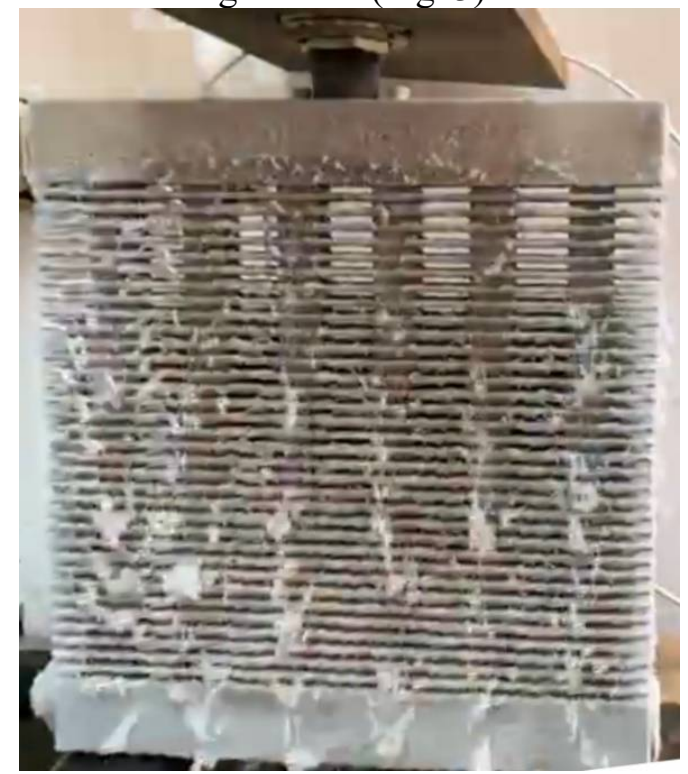

Fig. 3. De-icing of the heat exchanger using a magnetostrictive emitter with a perimeter core

As can be seen from the illustration, exposure to the emitter releases ice crusts from the heat exchanger surface within a few seconds and the ventilation equipment can be operated as before.

\section{Conclusions}

Production of 49K2F permendur packages is possible by means of electroerosion cutting, in this method samples do not require further machining and changes in the metal structure do not have significant changes. This method can be used for small-scale production of magnetostriction radiators for individual orders and pilot batches. The use of magnetostrictive emitters in air handling units with heat recovery makes it possible to increase the return of lost heat energy by at least 2.0 to 2.5 times and expands the geographical range of application for air-source heat pumps as well as in industrial air-conditioning units. The tried-and-tested anti-frostbite method protects the compression equipment from fluid intrusion into the suction lines, which is the main reason for the reduced service life of heat pump equipment.

\section{References}

1. Preobrazhensky A.A., Bishard E.G. Magnetic materials and elements: Textbook for university students in specialities. "Semiconductors and Dielectrics. 3rd ed. revised and supplemented. M.: Vyssh. shk. 1986. 352 p.

2. Giles D.S., Atherton D.L. (1984-03-15). "Theory of ferromagnetic hysteresis (invited). Journal of Applied Physics. 55 (6). 2115-2120.

3. Chizhov A.V., Pecherskaya R.M. Method of determination of maximum magnetic permeability of permalloys in constant magnetic field. Scientific and Technical Bulletin of the Volga Region. 2014. No. 3. P. $202-206$.

4. Starodubtsev Yu.N. The world of materials and technology. Magnetically soft materials. M.: Technosphere. 2011. $664 \mathrm{p}$. 
5. Mishin D.D. Magnetic materials: Textbook for universities. 2nd ed. revised and supplemented. M.: "Higher School". 1991. 384 p.

6. Bell System Technical Journal. American Telephone and Telegraph Co. 2020.15 (1).113 - 135.

7. Han F., Chen L., Zhou. X. Basic research on a pulse generator for micro-EDM. International Journal of Advanced Manufacturing Technology. 2006. 33 (5-6). 474

8. Sayegh M.A. et al. Heat pump placement, connection and operational modes in European district heating. Energy and Buildings. 2018. 166. P. $122-144$.

9. Jiang Y., Huiying F.U., Yao Ya., Yan L., Gao Q. Experimental study on concentration change of spray solution used for a novel non -frosting air source heat pump system. Energy and Buildings. 2014. 68. P. 707 - 712.

10 Chizhov A.V. Heat treatment of $\mathrm{Fe}-\mathrm{Co}-\mathrm{V}$ as a tool to improve the quality of products from magnetically soft materials. Engineering Herald of the Don. 2014. No. 2.

11. Ilina T.N., Mukhamedov R.Yu., Verevkin O.V. Prospects of using heat pumps in heating systems of lowrise residential buildings in Belgorod region. Bulletin of BSTU named after V.G. Shukhov. 2009. No. 3. P. $142-$ 146.

12. Minko V.A., Ilyina T.N., Potapova O.N. Analysis of methods of utilization of heat from technological equipment in systems of creation of microclimate in production shops of dairy plants. Bulletin of BSTU named after V.G. Shukhov. 2009. No. 4. P. $109-112$.

13. Orlov P.A., Uvarov A.V., Ilyina V.A., Orlov V.A., Orlov K.P., Orlov S.P. Impact of installation and use of geothermal heat pumps on ecology: Interuniversity International Congress. Higher School: Research, Moscow, 10 December 2020. Moscow: Infinity Publisher. 2020. 1. P. 136 - 147.

14. Orlov. K.P. Invention patent 2724661, Russian Federation. A way of protecting against icing on refrigeration and ventilation units; application dated 19.06.2019. № 2019119135.

15. Orlov P.A., Ilyina T.N., Orlov K.P. Impact of mechanical vibrations on icing of air-source heat pumps. Bulletin of BSTU named after V.G. Shukhov. 2021. 6 (6). P. 36 - 44. DOI.10.34031/2071-7318-2021-6-6-36-44.

For citation: Il'ina T.N., Orlov P.A., Chizhov A.V. Influence of material structure on the magnetostrictive properties of a radiator for defrosting heat exchangers of ventilation equipment. Construction Materials and Products. 2021.4 (4). P. 5 - 10. DOI: 10.34031/2618-7183-2021-4-4-5-10

Поступила в редакиию 5 июня 2021 г.

Принята в доработанном виде 2 июля 20212.

Одобрена для публикащии 1 августа 2021 г.
Received: June 5, 2021.

Revised: July 2, 2021.

Accepted: August 1, 2021. 